Original Research Paper

\title{
An Integrative Approach to the Study of Individuality of Subjects of Educational Activity in the Ontogeny from the Positions of Sex and Gender
}

\author{
Lubov Vladimirovna Mishchenko \\ Institute of Human Nature Studies, Pyatigorsk State Linguistic University, Pyatigorsk, Russian
}

\section{Article history}

Received: 05-02-2016

Revised: 09-04-2016

Accepted: 27-05-2016

Email: mitschenko@yandex.ru

\begin{abstract}
Scientists are trying to study the peculiarities of men and women by adding biological and social components of the human, however since gender is not the natural givenness, but a social construct assuming selfawareness and self-determination, the connections between these components will be refracted through a variety of conditions. The purpose of the article is an integrative study of non-linear relationship of biological and social characteristics of socialization and individualization in development of students of different sexes at different periods of their development based on psychological research. The nature of non-linear relationships was investigated in our study, using discriminant, correlation and factor analyses. The linear relationships were studied using Student's ttest for the control comparison. We have created models of sex and gender structure of integrated individuality of the taught boys and girls from preschool age to adolescence and conducted their comparative analysis. The psychological development programs have been developed that change the personality structure, increasing the number of flexible non-linear interdependencies of the biological and the social. Based on the research, we found that individuality of students with low level of development is characterized mainly by a high degree of genetic determination of the set of natural properties and a high role of objective conditions. High level of individuality development is characterized by non-linearity of interdependent biological and social properties and students of different sexes have their own specifics at different periods of their development. The essence of the author's approach to the training and education of the students is that the study of variable, multi-level non-linear relationships of the individuality's properties determines the specificity of social and biological potentiality of boys' and girls' development and opens great opportunities for the creation of optimum adaptation conditions of students in the educational environment and effective modalities for the training and education of students of different sexes.
\end{abstract}

Keywords: Integrative Psychology, The Theory of Integrated Individuality, Psychology of Sexual Distinctions, Gender Psychology, AdaptiveCompensatory-Synergetic Tendency of Development, Subjects of Educational Activity, Convergence and Divergence Law, Ontogeny

\section{Introduction}

The relevance of the study is determined by deep transformations in the field of education, which requires a comprehensive understanding of the issues of studying integral individuality of preschool and primary school children, adolescents, seniors, students as subjects of educational activity. National Doctrine of Education in the Russian Federation until 2025 reflects the will of the state to take responsibility for the present and future of the national education and identifies multifaceted and timely development of children and youth as one of the 
most important goals of education. Determining the ways of learners' harmonious development, selfrealization and self-actualization to a large extent depends on their gender identity.

In Russian psychology such an area of scientific research as psychology of sex includes studying the features of men and women as representatives of a definite sex (Kletsina, 2009; Khaperskaya, 2013). Within another area-psychology of sexual differences-mainly psychological characteristics of behavior of the different sex people are studied (Ilyuin, 2010; Senkova, 2013). But it should be noted, that the specifics of the domestic psychologic research of sex is that the description and analysis of data relating to the category of sex have always been present, but not always were built into the overall research model. This means that multivariate impact of the sex factor was not always taken into account.

The gender psychology studies not only differences in the psychological features of men and women; it is focused primarily on those laws of personal development which are caused by the phenomena of sexual differentiation, stratification and hierarchization. (Znakov, 2004; Ilyuin, 2010; Kletsina, 2009; Mishchenko, 2013; Ozhigova, 2009; Voitov, 2013).

There are a large number of gender studies in the international gender psychology (Bem, 1993; Boles, 2013, Breedlove and Hampson, 2002; Cartwright, 2000; Ghosh, 2015; Eller, 2015; Lippa, 2001; Savic and Arver, 2011; Oswalt, 2010; Rosselli et al., 2010; Padawer, 2012; Sternberg and Kaufman, 2002; Whitchouse, 2001). Foreign psychologists are insistently trying to draw the attention of the scientific world to the need for investigating gender in education.

According to many scientists, the domestic education system also ignores the sexual peculiarities of learners, teaching and raising them without taking into account the fundamental law of nature and society-sexual dimorphism. Meanwhile, gender-based objective biological differences to a large extent determine the features of perception and processing of teaching information, resistance to adverse influences and so on (Bagreeva, 2013; Boyazitova, 2004; Ilyuin, 2009; Kletsina, 2009; Mishchenko, 2016). Representatives of the gender approach complain that educational establishments as social institutions aggressively reproduce rigid standards of the traditional culture in relation to femininity and masculinity through education, contribute to the formation of gender stereotypes of selfperception and self-esteem of learners' personality by sexual characters, which, in turn, eliminates the manifestation of learners' individuality in the choice of the life self-determination.

A comprehensive analysis of sex- and genderoriented studies shows that they are characterized mainly by the element-by-element analysis of individual properties of learners. In other words, from this point of view, these works represent the essence of the additive research, enabling to diagnose the multiple properties of the individuality of the opposite sex students and compare them, which makes it impossible to explore a holistic profile of representatives of male and female learners. In addition, reduction of the biological and the social is seen in the studies of sex and gender, i.e., narrowing the entire psychologic reality to something that is principal in it. Since the theoretical and methodological basis of the psychology of sex is a biodeterminist paradigm and gender studies are based on the socio-constructivist paradigm, then either biological or socio-cultural foundations are at the focal point of these or those studies. A "linear determinism" is seen here as well, i.e., striving to present the causes and consequences in the form of a one-dimensional chain.

However, a person is a complex system with a multilevel structure and an ambiguous system of relations and hence determination serves as a multi-faceted, multilevel, multi-dimensional one, including the phenomena of different orders, that is, a systemic determination. Thus, if we study the person in general from the positions of the systemic research, the issue of the role of the biological and social in the human development becomes pointless. The systemic approach allows investigating the individuality of men and women initially as a whole with regard to the most complex relationship of all its properties.

To overcome additivity, reductionism and linear determinism characteristic of gender and sex-oriented studies, theoretically productive and practically effective research concepts of the learners' holistic individuality are required depending on gender identity. Many psychological theories and concepts (Belous, 2009; Boyazitova, 2004; Merlin, 2005; Mishchenko, 2013; Whitchouse, 2001) justify the need for interdisciplinary and integrative approaches to the study of individuality of the opposite-sex people in the educational space. To emphasize the achievements of gender psychology, psychology of sex and integrative psychology of individuality, we used a synthesis of concepts and introduced the term 'sex and gender individuality' into scientific use (Mishchenko, 2013).

The purpose of the work is to study the multivariate, multidimensional and multilevel interconnections of biological and social properties of the students' individuality at the different levels of training depending on the gender identity, to correlate the identified patterns of correlations of social-biological and structuralfunctional characteristics with the laws of the holistic development of students of different sexes and to compare them. 


\section{The Basic Research Hypotheses Are:}

- The current state of studying human individuality in the educational space from the positions of sex and gender in the framework of different approaches allows creating a holistic concept of formation of sex and gender individuality in the participants to the educational activity in the ontogeny on the basis of their integration

- The integrative approach allows revealing characteristics of sex and gender structure of the learners' integrated individuality at different levels of development, conditions, methods and mechanisms for its formation and operation, the strategies and lines of its development

- Sex and gender individuality of the subject of educational activities is a self-organizing, selfdeveloping, multi-level hierarchical system with teleological and causal types of determination, flexible many-to-many relationships between its biological and social components

- Development of sex and gender structures of integrated individuality in the taught boys and girls has adaptive-compensatory, synergistic tendency at the different age stages and is headed in the activeresultative and reactive-resultative direction

- Development of sex and gender structures of integrated individuality in preschool children, pupils and students is subject to the law of convergence and divergence of the individuality's biological and social systems.

\section{Methods and Techniques}

To solve the formulated problems and verify the initial assumptions, a complex of methods was used mutually verifying and complementing each other. The theoretical research methods included theoretical comparison and collation of human individuality at the different ontogenetic stages from the positions of sex and gender, compilation and interpretation of the psychologic, pedagogic, scientific and methodological literature on the research problem, forecasting, modeling and designing. The empirical research methods included: Empirical identification of uniqueness of integrated individuality structures in the preschool and primary school children, adolescents, seniors and students depending on their gender identity, age, objective and subjective conditions; empirical determination of systemic factors ensuring harmonization and dynamic equilibrium of sex and gender structures of the person's integrated individuality.

The personality of students studied by us included several levels of properties: Neurodynamic (properties of the nervous system), psychodynamic (the temperament), secondary properties of the individual (cognitive processes), personality (the character) and sociopsychological level (communicative properties) (Merlin, 2005). Therefore we studied intra- and inter-level interconnections.

The findings of the study were subjected to computer mathematical and statistical processing using Microsoft Word, Excel and SPSS 20 application software. Sex and gender individuality was studied in the interrelation of Psychodynamic Level (PDL), the Person's Secondary Qualities (PSQ), Personality Levels (PL), Socio-Psychological Levels (SPL) of the personality using Student's t-test (to determine the statistical significance of differences in individual indicators of integrated individuality of the trained boys and girls). To highlight the complex measurements in the structures of learners' integrated individuality we used discriminant analysis (according to the formula proposed by O.M. Kalinin):

$$
Z k=\sum_{i=1}^{n} \frac{a^{i_{1}}-a^{i_{2}}}{\delta_{i}^{2}} * X_{k}^{i}
$$

Where:

$a_{1}=$ An arithmetic mean of (i-th) of an individual parameter of the 1 st group

$a_{2}=$ An arithmetic mean of (i-th) of an individual parameter of the 2nd group

$\delta_{I}=$ Root mean-square deviation per totality of i-th parameters in the 1st and 2nd groups

$X_{k}^{i}=$ Absolute expression of each ratee by each parameter

$i=1,2,3, \ldots n$ ( $n$ is number of parameters)

$k=$ The ratee's number

$\Sigma=$ summation on all controlled parameters.

To study the character and specifics of the relationship of properties of sex and gender structures of integrated individuality of boys and girls we used correlation analysis by Karl Pearson. Correlation density was calculated using the following formula (Belous, 2009):

$$
X=\frac{m \cdot 100 \%}{k}, k=\frac{n^{2}-n}{2}
$$

Where:

$M=$ A number of significant correlations

$k=$ Maximum possible number of correlations

$n=$ A total number of parameters.

Factor processing of the initial data (system analysis), allowed us to identify a nonlinear correlation of properties and levels of integrated individuality of boys and girls on a comprehensive and compact basis. 
The factor analysis was carried out according to Thurstone. The results were studied by three criteria:

- $\quad$ By the average saturation of each level of integrated individuality with significant factor weights; the greater the average value of the integrated individuality level, the higher its adaptive significance; the average value of saturation with significant factor weights for the integrated individuality levels was calculated by the formula (Belous, 2009):

$$
X=\frac{(100 \%) \times k}{(n) m}
$$

Where:

$n=$ The number of indicators in the sample

$k=$ The number of significant factor weights according to the levels of integrated individuality taken separately

$m=$ The number of indicators at each level of integrated individuality.

- By the representation of specific multi-level properties of integrated individuality for each factor; the more complete the factor structure, the more developed and harmonious is the integrated individuality

- $\quad$ By the nature of inter-factor relations of integrated individuality's properties (orthogonal or oblique ones); orthogonal relations narrow and limit the abilities of a person, in turn oblique relations are flexible and plastic to adapt to the changing conditions of the subjective situation.

The research involved 2,845 subjects of educational activities (560 preschool children, 391 junior pupils, 494 teenagers, 275 senior pupils, 1125 high school students) at different stages of ontogeny. The study was conducted from 1993 to 2015 in kindergartens, schools and universities in the cities of Kabardino-Balkaria, the Stavropol Territory and the Krasnodar Territory of the Russian Federation.

\section{Results}

During several years we have carried out numerous studies of peculiarities of the sex and gender structures of integrated individuality of preschool and primary school children, adolescents, seniors and students depending on the subject's properties and the objective requirements of the activities (Mishchenko, 2013; 2016). Using the above-described mathematical and statistical methods, we carried out:
- Comparative analysis of sex and gender structures of preschoolers' integrated individuality depending on the level of semantic language development; the level of imagination development and game skills in a play, learning and development activities.

- Comparative analysis of sex and gender individuality of junior pupils with a high and low learning motivation; high and low cognitive activity in the learning conditions.

- Comparative analysis of sex and gender individuality of teenagers who were successful and unsuccessful in learning activity; active-resultative (laureates and winners of music competitions) and potentially resultative (gifted, but rarely winning in music contests) teenager musicians in the conditions of traditional, innovative, complementary and music education.

- Comparative analysis of sex and gender individuality of seniors with high and low social activity, with high and low aggressiveness, as well as with the different level of well-formedness of life goals in the conditions of learning and socially useful activity.

- Comparative analysis of sex and gender individuality of students, depending on the level of creativity development, competitiveness, who were satisfied and unsatisfied with learning activities at the beginning and end of studies in the universities of science and humanities.

As a result of the research we have found differences in sex and gender structures of integrated individuality of the taught boys and girls, depending on the objective and subjective conditions, with the help of Student's t-test and discriminant, correlation and factor analyses.

It is clearly illustrated by the diagram, drawn up based on the results of the correlation analysis (Fig. 1):

The data of conducted numerous studies allowed revealing adaptive-compensatory-synergetic tendency in the development of sex and gender structures of learners' integrated individuality in the active-resultative and reactive-resultative direction.

Active-resultative direction. In the context of the systemic approach, a useful result of the system is a system-forming factor, guiding the interaction of components in the system. From the standpoint of the principle of activity, the learners' individuality development is not just a process of adaptation to the environment, but the creation of their life, selfactualization, the implementation of internal programs not only due to external conditions, factors and stimuli, but in spite of them.

Reactive-resultative direction is also based on a useful result, implemented in the process of system adaptation to the environment, but here the principle of reactivity comes into effect, according to which the 
individuality development is determined mainly by external stimuli, factors and environmental conditions.

Proceeding from such understanding of the problem, we have made an assumption that the adequacy in developing psychologic neoformations, social situation and the leading type of activity of the given age period acts as a systemic factor of sex and gender structures of integrated individuality, which guide, integrate and arrange the interaction of components in the system and yield a useful result for this system. Compliance with these conditions stimulates the development of the learners' individuality in the active-resultative direction. Violation of the adequacy in developing the leading age characteristics results in the reactive-resultative way of the learners' individuality development at the different age stages (Mishchenko, 2013).

This can be exemplified by the comparative analysis (based on Thurstone's factor analysis) of sex and gender structures of integrated individuality in boys and girls with high and low imagination level and in the experimental group, where we arranged the psychological follow-up of children having low level of imagination with regard to sex and gender peculiarities, with the control group of boys and girls with low level of imagination, where formative assessment was not carried out. The table clearly shows that the control group develops in the reactive-resultative direction, whereas the experimental group moves in the active-resultative direction and according to the level of development approaches the baseline group, i.e., the children having high level of imagination (Table 1).

Another regularity that was indicated on the basis of the experimental data shows that sex and gender structures of integrated individuality of boys and girls in the process of their development are subject to the convergence and divergence law. Convergence is evident in the case when adequately developed leading age characteristics, acting as system-forming factors of sex and gender structures of the learners' individuality stimulate the formation of a large number of many-tomany relationships between the properties of the natural and social levels, which results in the convergence of the biological and social characteristics of the learners' integrated individuality with the dominant role of the social. In violation of the adequacy of the leading age characteristics the divergence of the natural and social occurs and sex and gender peculiarities in these structures of individuality are characterized by rather close relationship between the parameters of the natural subsystem of integrated individuality.

This can be exemplified by the research results for sex and gender individuality structures of juniors with high and low levels of academic motivation development. Most many-to-many relationships appear in highly-motivated children primarily between Psychodynamic (PDL) and Socio-Psychological Levels (SPL), between the Person's Secondary Qualities (PSQ) and Personality Levels (PL), which results in the convergence of the natural and the social in the boys' and girls' individuality, while their sex and gender peculiarities blend in this case. Juniors with low level of academic motivation development demonstrate less many-to-many relationships and they are mainly between the psychodynamic level of individuality and secondary qualities of the individual. As a result, the natural and the social diverge in the sex and gender structures of their integrated individuality. Sex and gender peculiarities become most pronounced in such structures of schoolchildren's individuality (Fig. 2 and 3).

Table 1. Factor structures of sex and gender individuality in preschool boys and girls depending on the level of imagination development before and after the formative assessment

\begin{tabular}{|c|c|c|c|c|c|c|c|c|}
\hline \multirow{2}{*}{$\begin{array}{l}\text { Criteria of preschool children's integrated individuality } \\
\text { development depending on the level of imagination } \\
\text { and in the context of psychological follow-up }\end{array}$} & \multicolumn{4}{|c|}{$\begin{array}{l}\text { Adaptive significance } \\
\text { of the levels }\end{array}$} & \multicolumn{2}{|c|}{$\begin{array}{l}\text { Factor } \\
\text { representation }\end{array}$} & \multicolumn{2}{|c|}{$\begin{array}{l}\text { Nature of inter- } \\
\text { factor relations }\end{array}$} \\
\hline & PDL & PSQ & PL & SPL & Complete & Partial & Oblique & Orthogonal \\
\hline Boys with high level imagination (baseline group) & 1.34 & 1.67 & 1.77 & 1.62 & 3 & 0 & 14 & 16 \\
\hline Girls with high level imagination (baseline group) & 1.66 & 1.67 & 1.77 & 1.70 & 3 & 0 & 14 & 16 \\
\hline $\begin{array}{l}\text { Boys with low level of imagination before the } \\
\text { experiment (experimental group) }\end{array}$ & 2.20 & 0.92 & 1.33 & 1.33 & 2 & 1 & 8 & 20 \\
\hline Boys after the experiment (experimental group) & 1.39 & 1.85 & 1.55 & 1.7 & 3 & 0 & 14 & 15 \\
\hline $\begin{array}{l}\text { Girls with low level of imagination before the } \\
\text { experiment (experimental group) }\end{array}$ & 2.22 & 0.92 & 1.55 & 1.25 & 2 & 1 & 10 & 16 \\
\hline Girls after the experiment (experimental group) & 1.67 & 1.85 & 1.78 & 1.70 & 3 & 0 & 14 & 15 \\
\hline $\begin{array}{l}\text { Boys with low level of imagination before the } \\
\text { experiment (control group) }\end{array}$ & 2.20 & 0.92 & 1.33 & 1.33 & 2 & 1 & 8 & 20 \\
\hline $\begin{array}{l}\text { Boys with low level of imagination after the } \\
\text { experiment (control group) }\end{array}$ & 2.22 & 1.11 & 1.33 & 1.33 & 2 & 1 & 9 & 19 \\
\hline $\begin{array}{l}\text { Girls with low level of imagination before the } \\
\text { experiment (control group.) }\end{array}$ & 2.22 & 0.92 & 1.55 & 1.25 & 2 & 1 & 10 & 16 \\
\hline $\begin{array}{l}\text { Girls with low level of imagination after the } \\
\text { experiment (control group) }\end{array}$ & 2.22 & 1.29 & 1.55 & 1.41 & 2 & 1 & 10 & 20 \\
\hline
\end{tabular}




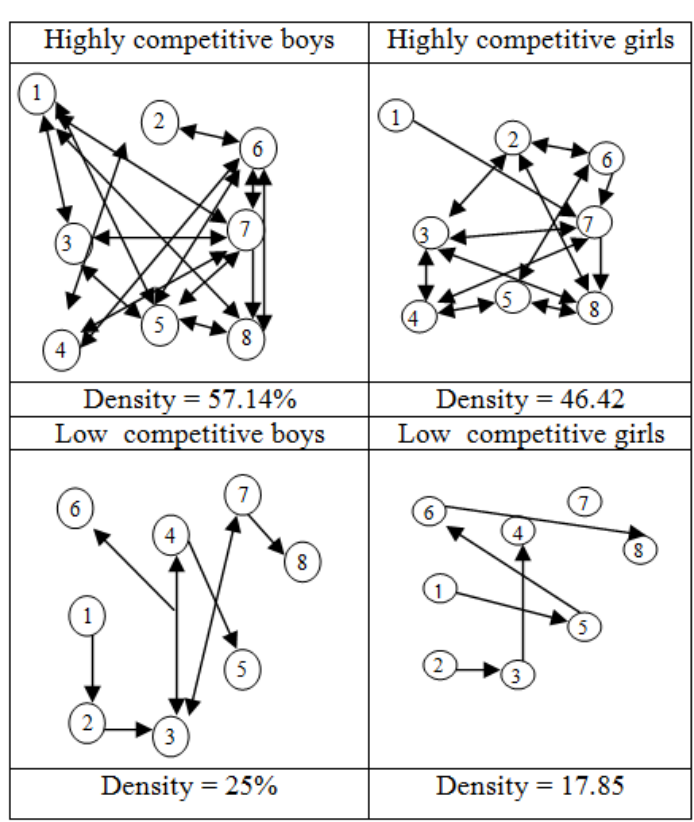

Fig. 1. Correlation scheme for personal level of sex and gender structure of individuality of male and female students with high and low competitiveness levels

$$
\text { - Boys - - - Girls }
$$

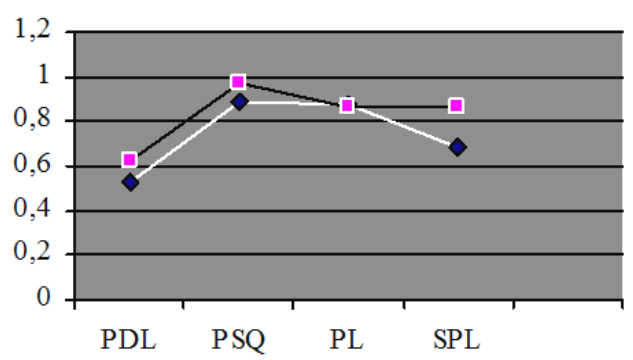

Fig. 2. Average value of factor weight representation for each level of sex and gender individuality of highlymotivated boys and girls
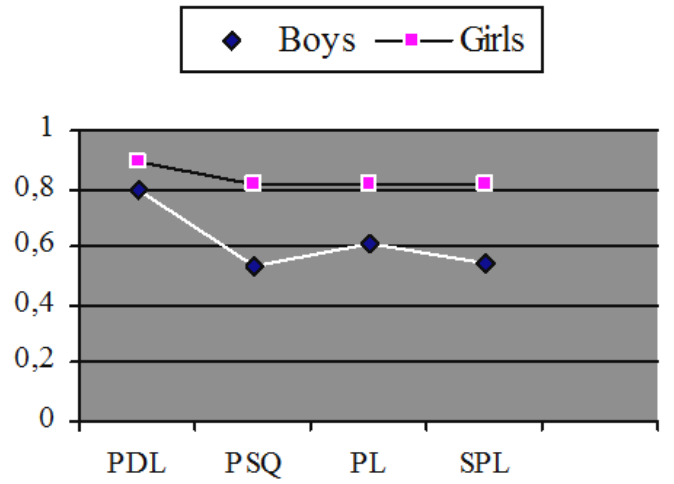

Fig. 3. Average value of factor weight representation for each level of sex and gender individuality of low-motivated boys and girls
The results of studying students confirmed adaptive-compensatory-synergetic tendency in the development of sex and gender structures of their integrated individuality in the active-resultative and reactive-resultative direction.

In the first year, a new social situation of development is created for students as a leading type of activity, personal neoformations are established in accordance with the dominant motive-the motive of preserving the status of the student, i.e. at the beginning of university studies sex and gender structures of students' integrated individuality develop mainly in the reactive-resultative direction. At the initial stage of studying at high school the natural levels play a dominant role in the organization of sex and gender structures of integrated individuality and its adaptation to the new environment. Freshmen try to adapt to the new social situation of development, enter into the new activities in accordance with their own peculiarities of the nervous system and temperament, concealing at first their personal qualities, which fail to facilitate survival in the new environment and preservation of the status of a student. Sex and gender peculiarities in the structures of boys' and girls' integrated individuality at this stage of development are characterized mainly by a high degree of genetic determination of a set of natural properties.

At the end of the studies, students are on the verge of changing the social situation of development, leading activities. Their personal neoformations are established in accordance with the dominant motive of professional development, increase in competitiveness, selfactualization. Sex and gender structures of the students' integrated individuality at the final stage of university studies are developed in the active-resultative direction. At the end of the studies the personality level, the socio-psychological level and the person's secondary qualities have the highest adaptive significance in the structures of the graduates' integrated individuality. Graduates vindicate now their personal worth, intelligence, uniqueness. At this stage of development sex and gender peculiarities in the structures of boys' and girls' integrated individuality are characterized primarily by a high degree of determination of the set of social and intellectual virtues.

Investigations of sex and gender structures of students' individuality confirmed operation of the convergence and divergence laws. The convergence law manifests itself in the sex and gender structures of the freshmen studying at the universities of humanities and natural sciences. At the beginning of studies the survival motive stimulates development of the boys and girls in similar direction, blurs sex and gender differences, however, it should be noted that in the humanities university this process is not so pronounced as in the university of natural sciences (Fig. 4 and 5). 


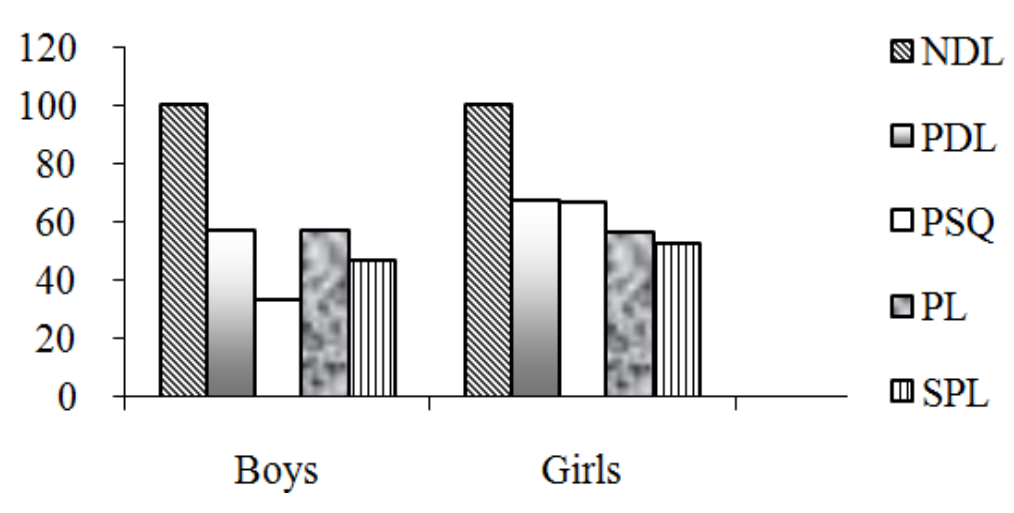

Fig. 4. Intra-level density of correlations between various properties of sex and gender individuality girls and boys studying at the humanities university, the initial stage of university studies, (\%); Note: NDL-Neurodynamic Level of integrated individuality; PDL-Psychodynamic Level of integrated individuality; PSQ-Person's Secondary Qualities of integrated individuality; PL-Personality Level of integrated individuality; SPL-Socio-Psychological Level of integrated individuality

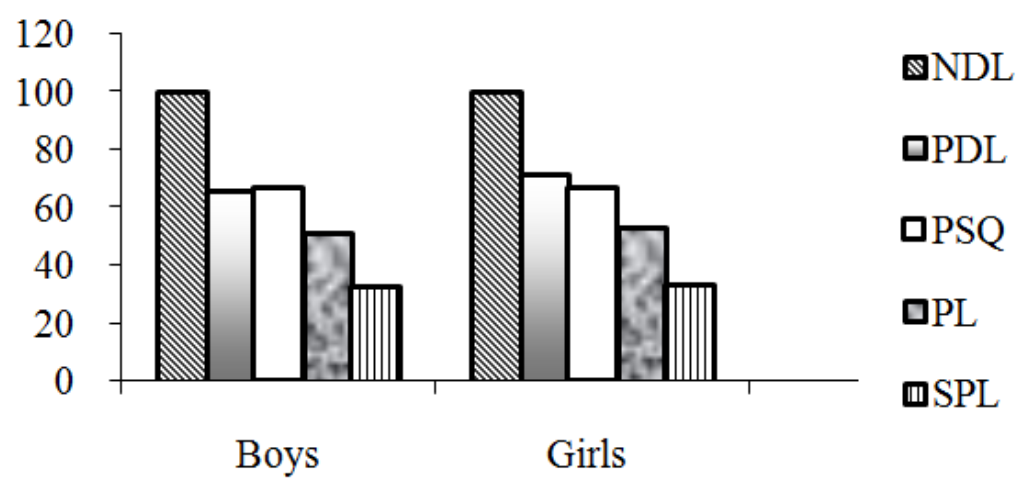

Fig. 5. Intra-level density of correlations between various properties of sex and gender individuality girls and boys studying at the university of natural sciences, the initial stage of university studies, (\%); Note: NDL-Neurodynamic Level of integrated individuality; PDL-Psychodynamic Level of integrated individuality; PSQ-Person's Secondary Qualities of integrated individuality; PL-Personality Level of integrated individuality; SPL-Socio-Psychological Level of integrated individuality

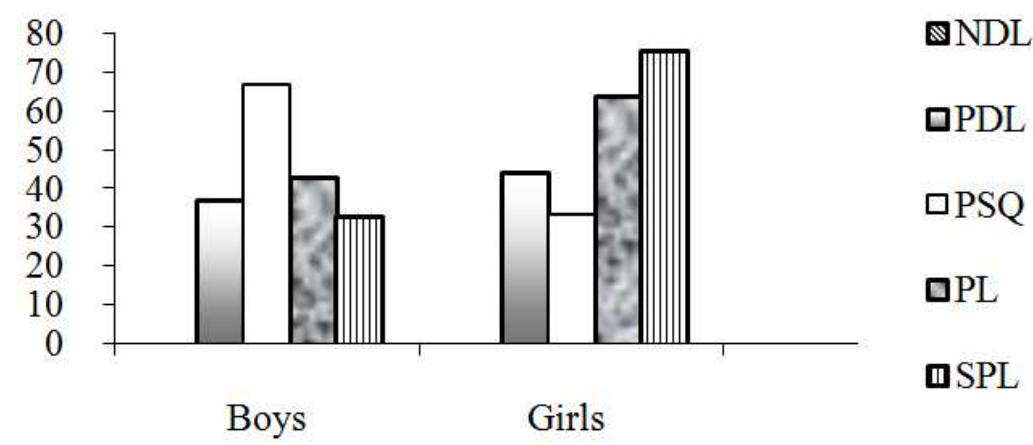

Fig. 6. Intra-level density of correlations between various properties of sex and gender individuality girls and boys studying at the humanities university, the final stage of university studies (\%); Note: NDL-Neurodynamic Level of integrated individuality; PDL-Psychodynamic Level of integrated individuality; PSQ-Person's Secondary Qualities of integrated individuality; PL-Personality Level of integrated individuality; SPL-Socio-Psychological Level of integrated individuality 


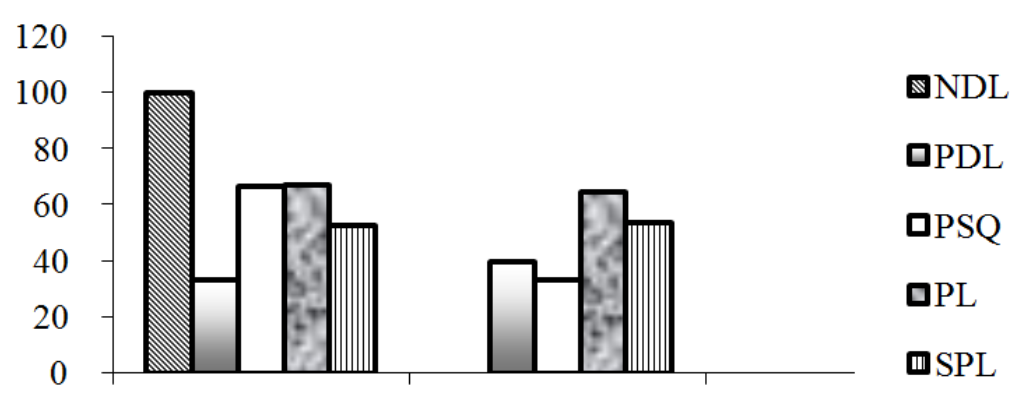

Boys

Girls

Fig. 7. Intra-level density of correlations between various properties of sex and gender individuality girls and boys studying at the university of natural sciences, the final stage of university studies (\%); Note: NDL-Neurodynamic Level of integrated individuality; PDL-Psychodynamic Level of integrated individuality; PSQ-Person's Secondary Qualities of integrated individuality; PL-Personality Level of integrated individuality; SPL-Socio-Psychological Level of integrated individuality

The divergence law manifests itself in the sex and gender structures of graduates studying at the universities of humanities and natural sciences. At the end of studies motive of professionalization differentiates the boys' and girls' development, stimulating manifestation of sex and gender distinctions (Fig. 6 and 7).

Figure 4-7 show the correlation density (percentage on the y-axis) of the investigated levels in sex and gender structures of integrated individuality of male and female students (indicated on the $\mathrm{x}$-axis). These parameters describe how tightly organized the relations are between the properties of integrated individuality of male and female students.

On the basis of numerous experimental studies we have determined the uniqueness of sex and gender structures of integrated individuality of preschool and primary school children, adolescents, seniors and students. This uniqueness depends on the objective conditions of activity (activity in the context of innovative, traditional and supplementary education, games, training, developing activities). Dynamical equilibrium of integrated individuality structures in different conditions of activity in girls is provided mainly by adaptive activity, integrating role of the personality and socio-psychological levels, coherence in the interaction of all levels. In boys it is provided by the personality and the natural levels and consistency in the interaction of all levels. The age factor in this case also differentiates the process of adapting to the various conditions of boys' and girls' activity.

It was found that restructuring of sex and gender individuality in boys and girls of different ages proceeds at similar rates and in qualitatively similar direction under the influence of modern psychological and pedagogical technologies. However after the formative assessment the content of variations in the sex and gender structures of their integrated individuality is different.
We have defined conditions for effective developing programs; they perform the system-forming function in the harmonization of multi-level properties of the learners' sex and gender individuality only if its execution becomes a positive motivation. Specificity of forming the socio-typical motives is determined by the desire for knowledge and innovation in boys and by personal and socio-psychological involvement in girls.

As a result of the studies, we have established the role and functionality of the subject' properties in forming the learners' sex and gender individuality at the different educational stages. The subject' properties, performing a system-forming role, have a specific impact on the learners' individuality development depending on their gender identity at the different ontogenetic stages. With the high level of development of the subject's properties, such as imagination, semantic speech, strong-willed regulation, game skills in preschool children; motivation of learning activities, cognitive activity in primary school children; musical talent, desire for success in adolescents, social activity, maturity of life goals in seniors; creativity, competitiveness and satisfaction with educational and professional activities in students, sex and gender peculiarities blur in boys and girls and at a low level of development they become prominent (Mishchenko, 2016).

\section{Discussion}

The integrative sex and gender approach allows investigating male and female individuality in a constantly changing world; a person can be considered as an independent system, which is in turn a part of a much larger system where all the elements are interconnected, interdependent and affect each other (Merlin, 2005). Society, like any evolving system must, on the one hand, maintain a state of stable equilibrium, stability and on the other hand, be ready to change. The system is able to remain stable through changing its 
structure. At the various stages of the society development men and women, as the elements of this system, are personification of typical masculinity and femininity to a greater or lesser extent. Through the stereotypical behavior of men and women the society maintains its sustainability, stability, security and at the same time, it allows for greater variability of sex and gender behavior that enables it to change (Lippa, 2001; Bem, 1993; Ghosh, 2015).

The problem of learners' integrative study depending on their sex and gender identity is extremely relevant for the science. The education system not always takes into account both objective biological differences of the learners and socially determined gender peculiarities, though both influence the specifics of perception and processing of academic information. Abstracting from them leads to the underestimation of significant individual differences of the learners and, consequently, to the unification of pedagogical impact.

Influence of sex and gender peculiarities on the style characteristics of the information up taking process, the strategy selection for psychological adaptation and coping have long been a subject of study in psychology and this influence is difficult to overestimate when implementing pedagogical design of the educational environment at the institution. Adaptive capabilities of the personality are deeply individual and differ in students depending on their sexual distinctions and gender identity. The ways how they will be used and how they will contribute to the success of self-realization at the different stages of learning depend on integration of the educational subject's adaptive capabilities at all levels and the unique interaction of multi-level characteristics of human individuality, reflecting the relationship of individual, personal and sociopsychological manifestations in the activities.

The elaborated paradigm of theoretical provisions, methodological tools and empirical results deepens and expands the current understanding of psychological factors and the means of development, regularities and processes of the human individuality formation and functioning at different age levels in the educational space from the positions of sex and gender. The fact that sex and gender structures of the learners' integrated individuality at all the studied levels of age development are variable and their uniqueness depends on the conditions and the nature of the interaction between the internal and external conditions, on the dialectical unity of the objective and the subjective conditions of the schoolers' leaning activity and living environment, on the integrated ratio of the major tendencies in the individuality development at a certain stage of ontogeny is of considerable informative interest.

Scientifically justified systemic factors provide harmonization and dynamical equilibrium with regard to sex and gender structures of human integrated individuality at the different academic stages. They are based on the integrity and flexibility of the structure of sex and gender individuality (dominance of flexible oblique relations and low number of rigid orthogonal ones, increase in the density of multi-level relations; enhancement of adaptive capacity of the personality and socio-psychological levels) (Shchebetenko, 2007).

It was found for the first time that sex and gender development of learners' integrated individuality structures at the different ontogenetic stages is subject to the adaptive-compensatory-synergetic tendency and proceeds in the active-resultative or reactive-resultative direction. The article contains new ideas conforming that the development of sex and gender individuality of the taught boys and girls is subject to the convergence and divergence law. Uniqueness of sex and gender individuality in preschool and primary school children, adolescents, seniors and students was determined experimentally in the context of implementation of various social and personality-significant activities.

The methodology of the proposed approach can be called an integrative-structural one. The category of integration suggests that parts 'comprising' the whole have specific features which provide the possibility of certain links arising between them. The effect of the integration is manifested, on the one hand, in the fact that a part of the whole loses some properties or they are transformed and, on the other hand, in the fact that the integrity itself acquires new properties generated mainly by those relations that have arisen when parts were entering this formed whole (Merlin, 2005). Thus, the integrative process taking place "inside" the structure of a complex object is a mechanism of its existence and a prerequisite for a number of qualitatively new (systemic) properties appearing in this object.

The interdisciplinary nature of integrative psychology of the human individuality development reflects the general tendency of modern science, strengthening of integrative processes, the mutual interaction and interpenetration of different areas of knowledge in the study of a common object of research (Cartwright, 2000; Sternberg and Kaufman, 2002; Padawer, 2012; Rosselli et al., 2010; Whitchouse, 2001). The logic of scientific research leads to the synthesis of a number of sciences, the formation of dialectically interconnected complex of scientific concepts about individuality of men and women, as an integral and diverse system. Each of sciences, contacted by psychology of sex and gender development of human individuality, makes it possible to deepen the knowledge of the phenomena with that necessary component and the background for the development of scientific achievements, discoveries, works of genius, which the scientific heritage is so rich in. The generalization of scientific knowledge of 
psychology of sex, gender psychology, psychology of integrated individuality and integrative psychology of development into a single whole is able not only to identify and eliminate gaps, white spots of the latter on the borders of the traditional sciences, but also to expand the horizons in researching individuality of men and women in the ontogeny through the integration of knowledge and applied technologies of these sciences.

Integrative psychology of individuality' sex and gender development inherits and develops ideas, principles, methods and techniques of sciences, knowledge of which it integrates, allows theoretically comprehending and analyzing all the methods and techniques for studying individuality of men and women. It also creates new methods of integrative psychology of sex and gender development of human individuality, being adequate to its object (Boyazitova, 2004).

At the same time, the proposed integrative psychology of human individuality's sex and gender development essentially differs from other interdisciplinary areas in that its terminology and methods are based on the achievements of non-linear mathematics and those sections of the natural sciences and humanities, which study the processes of development of complex systems (Breedlove and Hampson, 2002; Oswalt, 2010).

\section{Conclusion}

Thus, the present state of studying human individuality in the Russian educational space from the positions of sex and gender, the described and conceptually interpreted results of the carried out methodological, theoretical and experimental studies have allowed us to argue that learners' sex and gender individuality activities in the ontogeny is a selforganizing, self-developing, multi-level hierarchical system with teleological and causal types of determination, flexible, many-to-many relationships between its biological and social components. Teleological type of determination justifies the nonlinearity of the relationship of its socio-biological, structural and functional characteristics with the development regularities.

The studies revealed that the uniqueness of sex and gender structures of integrated individuality of preschoolers, juniors, adolescents, seniors and students depends on the objective conditions of activity (activity in terms of innovation, traditional and supplementary education, play, learning, development activities, educational activities at the universities of natural sciences and humanities). In girls-teenagers and seniors-successful adaptation to the conditions of the activities is provided, mainly, by the diversity of correlations of personal and socio-psychological properties, in boys in most cases it is determined by the variety of correlations of personal and the natural levels. In girls of preschool, elementary school and college-age (fifth-year students) adaptation to the activity conditions is provided by the variety of correlations of social and psychological properties, secondary properties of the individual and coherence in the interaction of all levels. Adaptation of the male sample of these age periods is provided by correlation of personal properties, secondary properties of the individual and coherence in the interaction of all levels. In the freshmen students, regardless of gender, adaptation is ensured by the interaction of natural levels of integrated individuality.

The conducted research allowed us to conclude that sex and gender development of structures of the taught boys and girls integrated individuality at the different ontogenetic stages is subject to the adaptivecompensatory-synergetic tendency and is headed in the active-resultative or reactive-resultative direction, proceeding from the idea that a useful result of the system is a system-forming factor, guiding the interaction of components in the system. Adequacy in developing psychologic neoformations, social situation and the leading type of activity of the investigated age period act as systemic factors for development of sex and gender structures of integrated individuality in preschool and primary school children, adolescents, seniors and students, which guide, integrate and arrange the interaction of components in the system and yield a useful result for the system. Compliance with these conditions stimulates the development of individuality in the active-resultative direction. Violation of the adequacy in developing the leading characteristic of the age leads to the reactive-resultative direction of individuality development.

Novelty of the obtained results is revealed in the fact that development of sex and gender structures of the taught boys' and girls' integrated individuality is subject to the convergence and divergence law. Convergence manifests itself in the case when psychologic neoformations complying with investigated age period and adequate aspects of social situation, of the leading activity, stimulate the formation of a large number of many-to-many relationships between the properties of the natural and social levels which results in the convergence of the natural and social in these sex and gender structures with the dominant role of the social factor. In violation of the adequacy in development of the leading age characteristics they cease to fulfill the system-forming role in the learners' integrated individuality structures, thereby reducing the number of many-to-many correlations between the properties of the natural and social levels and diverging the natural and the social in 
the sex and gender structures of their integrated individuality. Sex and gender peculiarities in these individuality structures are characterized by rather close relationship between the parameters of the natural subsystem of integrated individuality.

Having implemented numerous programs of psychological support and psychological follow-up, we discovered that individuality of the taught boys and girls of different ages transforms under the influence of modern psychological and pedagogical technologies. The novelty of the conclusion is in the fact that restructuring proceeds at similar rates and in qualitatively similar direction, but after the formative assessment the content of variations occurred in the sex and gender structures of the male and female integrated individuality is different. Developing programs perform the system-forming function in the harmonization of multi-level properties of the learners' sex and gender individuality only if its execution becomes a positive motivation. Specificity of forming the socio-typical motives is determined for boys by the desire for knowledge and innovation and for girls-by personal and socio-psychological involvement.

\section{Acknowledgment}

The author would like to gratefully acknowledge the unknown reviewers for their review and helpful comments.

\section{Ethics}

This article is original and contains unpublished material. The author confirms there are no ethical issues involved.

\section{References}

Bagreeva, K.S., 2013. Role of semantic speech in the development of integrated individuality in preschool boys and girls. Proceedings of 9th International Scientific and Practical Conference, (SPC' 13), Publishing House, pp: 44-42.

Belous, V.V., 2009. Introduction into psychology of a polymorphous individuality. RAS-PSLU, Moscow, Pyatigorsk.

Bem, S.L., 1993. The Lenses of Gender: Transforming the Debate on Sexual Inequality. 1st Edn., Yale University Press, New Haven, ISBN-10: 0300061633, pp: 244.

Boles, J. and C. Tatro, 2013. Androgyny (Subsection Gender-Identity Formation). In: Men in Transition: Theory and Therapy, Solomon, K. (Ed.), Plenum Press, New York, pp: 99-129.

Boyazitova, I.V., 2004. Problems of integrative psychology of development. PSLU, Pyatigorsk.
Breedlove, S.M. and E. Hampson, 2002. Sexual Differentiation of the Brain and Behavior. In: Behavioral Endocrinology, Becker, J.B. (Ed.), The MIT Press, Cambridge, Massachusetts, London, England, pp: 75-116.

Cartwright, J., 2000. Evolution and Human Behavior: Darwinian Perspectives on Human Nature. 1st Edn., MIT Press, London, ISBN-10: 0262531704, pp: 376.

Eller, J.D., 2015. Culture and Diversity in the United States: So Many Ways to be American. 1st Edn., Routledge, New York, ISBN-10: 1138826685, pp: 356.

Ghosh, S., 2015. Gender Identity.

Ilyuin, E.P., 2010. Sex and Gender. 1st Edn., Piter, Saint-Petersburg.

Khaperskaya, D.V., 2013. Systemic study of integral individuality structure of students in high and low competitive groups in view of sex and gender differences. World Scientific Discoveries Krasnoyarsk, 9: 304-315.

Kletsina, I.S., 2009. Gender Socialization in the Education System: Hidden Curriculum. In: Gender Psychology, Kletsina, I.S. (Ed.), Piter, SaintPetersburg.

Lippa, R.A., 2001. On deconstructing and reconstructing masculinity-femininity. J. Res. Personality, 35: 168-207. DOI: 10.1006/jrpe.2000.2307

Merlin, V.S., 2005. Psychology of Individuality: Selected Psychological Works. Moscow Psychological Social Institute, Moscow.

Mishchenko, L.V., 2013. Theoretical and methodological problems of systemic study of sex and gender development of individuality in primary school children. Publishing House "Science and Innovation Center, St. Louis, Missouri, USA.

Mishchenko, L.V., 2016. Formation of sex and gender individuality of the subject of educational activities in the ontogeny. Publishing House "Science and Innovation Center", St. Louis, Missouri, USA.

Oswalt, A., 2010. Factors influencing gender identity.

Ozhigova, L.N., 2009. Semantic Mechanisms of Gender and Occupational Personal Fulfilment in the PolyEthnic Environment. 1st Edn., Kuban State University, Krasnodar.

Padawer, R., 2012. What's so bad about a boy who wants to wear a dress? The New York Times.

Rosselli, M., A. Ardila, G. Navarrete and M. Matute, 2010. Neuropsychological assessment of Spanish/English bilingual children in the United States. Arch. Clin. Neuropsychol., 23: 218-235. 
Savic, I. and S. Arver, 2011. Sex dimorphism of the brain in male-to-female transsexuals. Cerebral Cortex, 21: 2525-2533. DOI: 10.1093/cercor/bhr032

Senkova, M.P., 2013. Imagination of preschool boys and girls and its role in their integrated individuality development. Proceedings of the Materialy IX Mezinarodni Vedecko-Praktika Conference Psychologie a Sociologie: Praha. Publishing House "Education and Science" s.r.o.-Stran, pp: 37-39.

Shchebetenko, A.I., 2007. Inter-level Structures of Integrated Individuality. 1st Edn., Smysl, Moscow.

Sternberg, R.J. and J.C. Kaufman, 2002. The evolution of intelligence.
Voitov, A.S., 2013. Systemic approach to the research of sex and gender in junior schoolers with different level of learning motivation development. Novinata za naprednali nauka.

Whitchouse, H., 2001. The Debated Mind: Evolutionary Psychology Versus Ethnography. 1st Edn., Berg, New York, ISBN-10: 1859734278, pp: 229.

Znakov, V.V., 2004. Sexual, gender and personality distinctions in understanding a moral dilemma. Psychol. J., 25: 41-51. 